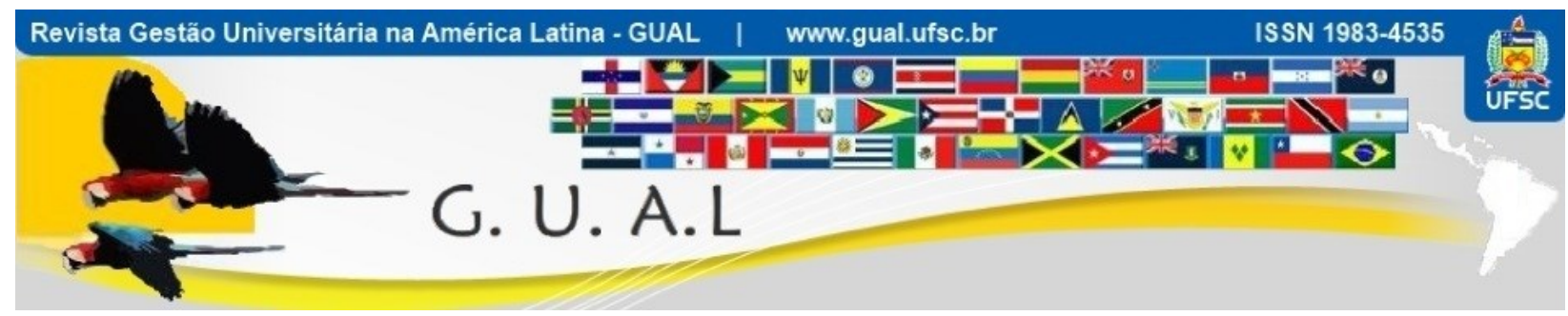

DOI: http://dx.doi.org/10.5007/1983-4535.2018v11n1p24

\title{
VALORES RELATIVOS AO TRABALHO E ÂNCORAS DE CARREIRA: A ÓTICA DE DISCENTES DO ENSINO SUPERIOR NAS MODALIDADES PRESENCIAL E À DISTÂNCIA
}

\section{WORK VALUES AND CAREER ANCHORS: THE PERSPECTIVE OF STUDENTS OF HIGHER EDUCATION IN CLASSROOM METHODS AND DISTANCE}

Tais de Andrade, Doutora

Universidade Federal de Santa Maria - UFSM

tais0206@gmail.com

Vania de Fátima Barros Estivalete, Doutora Universidade Federal de Santa Maria - UFSM vaniaestivalete@ufsm.br

Lisiane Pellini Faller, Doutora Universidade Federal de Santa Maria - UFSM lisifaller@gmail.com

Vivian Flores Costa, Mestre Universidade Federal de Santa Maria - UFSM Instituto Federal Farroupilha - IFFAR vivianfc13@gmail.com

Recebido em 31/maio/2016

Aprovado em 07/novembro/2017

Sistema de Avaliação: Double Blind Review

Esta obra está sob uma Licença Creative Commons Atribuição-Uso. 


\title{
RESUMO
}

O presente estudo leva em consideração os fatores que interferem nas decisões de carreira a partir das demandas internas dos indivíduos, representadas pelos valores relativos ao trabalho. Investigou-se a percepção dos discentes de cursos de graduação presencial e à distância sobre os valores relativos ao trabalho e as âncoras de carreira. Para tanto, utilizou-se uma survey junto a 958 discentes de graduação das modalidades presencial e à distância de instituições de ensino superior do interior do Rio Grande do Sul. O instrumento de coleta de dados foi elaborado a partir da Escala de Valores do Trabalho Revisada, desenvolvida por Porto e Pilati (2010) e o Inventário de Âncoras de Carreira proposto por Schein (1993; 1996). Quanto aos resultados, houve diferenças significativas entre as percepções das duas modalidades de ensino, mas a hierarquia atribuída aos valores e âncoras em ambas foi semelhante, o que demonstra certo padrão de concordância quanto à percepção de importância atribuída a cada dimensão estudada.

Palavras-chave: Valores Relativos ao Trabalho. Âncoras de Carreira. Ensino Presencial e à Distância.

\begin{abstract}
This study takes into account the factors that interfere with career decisions from the internal demands of individuals, represented by the work values. Investigated university students' perspective on work values and career anchors. For this, we used a survey along the 958 undergraduate students of face and distance higher education institutions in the interior of Rio Grande do Sul. The data collection instrument was developed from the Work Values Scale Revised developed by Porto and Pilati (2010) and the Inventory of Career Anchors proposed by Schein $(1993 ; 1996)$. As for the results, there were significant differences between the perceptions of the two methods of teaching, but the hierarchy assigned to the values and anchors in both was similar, which shows certain pattern of agreement as to the perception of importance attached to each dimension studied.
\end{abstract}

Keywords: Work Values. Career Anchors. Classroom Methods and Distance Learning. 


\section{INTRODUÇÃO}

O trabalho vem desempenhando nos últimos anos um papel central na sociedade, uma vez que através dele os indivíduos manifestam seus desejos, insatisfações, motivações e projetam metas pessoais, norteando o comportamento no ambiente de trabalho (PORTO; TAMAYO, 2008). Desse modo, as pesquisas relacionadas aos valores do trabalho apontam grande relevância nos estudos organizacionais por contemplarem a compreensão do mundo do trabalho e refletirem interesses dos indivíduos, tratando de princípios e crenças a respeito daquilo que deseja no trabalho (PORTO; TAMAYO, 2003; 2008).

Alguns estudos comprovaram a relação entre valores e carreira, com abordagens convergentes entre as trajetórias profissionais e as aspirações pessoais dos indivíduos (CHANG et al., 2011). Segundo Bendassolli (2009), a carreira é o resultado de um processo individual de significados, interpretações e experiências de vida levadas para o trabalho, o que aponta os valores humanos cada vez mais guiando as orientações profissionais (SOLDANO, 2011).

Ainda, de acordo com Abrahim (2009), a estrutura da personalidade e o autoconhecimento são responsáveis por suscitar o reconhecimento das demandas pessoais, as quais incluem as preferências de trajetória profissional. Da mesma forma, Wils, Wils e Tremblay (2010) e Toit e Coezee (2012) defendem que os indivíduos escolhem suas carreiras em função da importância dos seus valores, o que determinaria a influência dos mesmos sobre a definição das âncoras de carreira.

Diante destas perspectivas, o presente estudo leva em consideração os fatores que interferem nas decisões de carreira a partir das demandas internas dos indivíduos, representadas pelos valores relativos ao trabalho. Para Leuty e Hansen (2011), são poucos os estudos que dão expressão à compreensão dos valores relativos ao trabalho e também poucos aliam o tema às decisões de carreira (TOIT; COETZEE, 2012). Assim, o estudo dos valores relativos ao trabalho aliado às âncoras de carreira possibilita melhor entendimento sobre a influência das perspectivas individuais sobre as âncoras de carreira.

Em se tratando de instituições de ensino superior, considerando-se os discentes dos cursos de graduação nas modalidades presencial e à distância, a temática torna-se mais relevante, pois pode trazer contribuições acerca do melhor entendimento sobre os motivos que levam os alunos a trabalhar, os princípios orientadores de sua vida no trabalho e sua influência nas predisposições da carreira na atualidade. 
Para Hiltz (1993), o perfil do discente do ensino à distância geralmente traduz-se em indivíduos com mais idade e maturidade, portanto com condições de avaliar a real necessidade de fazer um curso à distância, uma vez que sabem que terão que estudar na maior parte do tempo sem o acompanhamento de um professor. Por outro lado, o discente do ensino presencial geralmente é mais jovem, tendo concluído recentemente o ensino médio, sem possuir experiência profissional, no caso dos cursos diurnos, ou trabalham e estudam, tendo muitas vezes ingressado precocemente no mercado de trabalho, no caso dos cursos noturnos (FERLIN; TOZZI, 2005).

Considerando as perspectivas que sinalizam distinções quanto ao perfil dos discentes das modalidades presencial e à distância, surgem algumas inquietações. Existem diferenças na percepção dos discentes das modalidades presencial e à distância em relação aos valores do trabalho? Quais as preferências profissionais e de carreira destes discentes?

Assim, tendo como objeto de estudo os discentes de cursos de graduação de instituições de ensino superior, públicas e privadas, nas modalidades presencial e à distância, buscou-se responder o seguinte problema de pesquisa: "Qual a percepção dos discentes de cursos de graduação presencial e à distância sobre os valores relativos ao trabalho e as âncoras de carreira?"

Diante disso, o presente estudo tem como objetivos: (i) verificar a percepção dos discentes em relação à hierarquia existente quanto aos valores relativos ao trabalho; (ii) identificar entre os discentes quais são as âncoras de carreira que prevalecem; (iii) verificar se existe distinção entre alunos dos cursos presenciais e alunos dos cursos à distância em relação aos valores relativos ao trabalho e às âncoras de carreira.

Destaca-se ainda que ao tratar da temática Valores Relativos ao Trabalho e Âncoras de Carreira, Andrade et al. (2014) analisaram a influência dos Valores Relativos ao Trabalho sobre as Âncoras de Carreira, a partir da perspectiva de discentes de instituições de ensino superior. No entanto, esta pesquisa difere do referido estudo por abordar os Valores Relativos ao Trabalho e as Âncoras de Carreira sob outra perspectiva, tendo como foco as distinções entre os alunos das diferentes modalidades acerca destas temáticas.

$\mathrm{Na}$ sequência, é apresentada uma revisão de literatura a respeito dos valores relativos ao trabalho, âncoras de carreira e modalidades de ensino presencial e à distância. Após, é apresentado o método de pesquisa utilizado, bem como a análise dos resultados encontrados. 


\section{VALORES RELATIVOS AO TRABALHO E ÂNCORAS DE CARREIRA: A ÓTICA DE DISCENTES DO \\ ENSINO SUPERIOR NAS MODALIDADES PRESENCIAL E À DISTÂNCIA \\ DOI: http://dx.doi.org/10.5007/1983-4535.2018v11n1p24}

Finalizando o trabalho, são detalhadas as considerações finais do estudo, limitações e sugestões para pesquisas futuras.

\section{VALORES RELATIVOS AO TRABALHO}

Os valores relativos ao trabalho referem-se aos princípios ou crenças sobre metas, recompensas e comportamentos desejáveis no trabalho, os quais refletem interesses e desejos dos indivíduos e guiam suas avaliações sobre os resultados e contexto do trabalho (PORTO; TAMAYO, 2003;2008).

De acordo com Elizur e Sagie (1999), os valores relativos ao trabalho são caracterizados como uma das facetas dos valores pessoais e resultam de experiências e processos individuais de socialização que ocorrem ao longo da vida (ROS, 2006). Assim, os valores "atuam como elementos integradores, no sentido de que são compartilhados por todos ou pela maioria dos membros organizacionais" (OLIVEIRA; TAMAYO, 2004, p. 130).

Com base nessa concepção de valores, Schwartz (1992, 2005) desenvolveu uma tipologia contendo dez tipos motivacionais de valores, organizados em uma estrutura bidimensional e bipolar: abertura à mudança (autodeterminação, estimulação e hedonismo) versus conservação (segurança, conformidade e tradição); e autopromoção (poder, realização e hedonismo) versus autotranscendência (universalismo e benevolência). A partir dos tipos motivacionais de valores propostos por Schwartz, Ros, Schwartz e Surkiss (1999) identificaram quatro tipos de valores relativos ao trabalho: intrínsecos (metas obtidas pelo conteúdo do trabalho/ abertura à mudança); extrínsecos (metas obtidas pelos resultados do trabalho/ conservação); prestígio (busca de relacionamentos interpessoais/ autopromoção); e social (busca pelo poder e reconhecimento através do trabalho/ autotranscendência).

Da mesma forma, com base na Teoria de Valores de Schwartz, Porto e Tamayo (2003) desenvolveram a Escala de Valores relativos ao Trabalho (EVT) em quatro dimensões, estabelecendo uma relação entre os valores individuais e os valores relativos ao trabalho para a realidade brasileira: realização no trabalho (busca de prazer, autonomia no trabalho estimulação e independência de pensamento); relações sociais (busca de relações sociais positivas e de contribuições para a sociedade); prestígio (busca de sucesso profissional, poder de influência e autoridade); e estabilidade (busca suprir necessidades pessoais materiais, segurança e ordem na vida). 
Por julgarem que os fatores da EVT não avaliavam satisfatoriamente todo o conteúdo teórico dos tipos motivacionais da Teoria de Valores de Schwartz e pelo fato de as dimensões da EVT não apresentarem as correlações negativas esperadas entre os fatores de polos opostos nos estudos de Porto e Tamayo (2007), Porto e Pilati (2010) desenvolveram a Escala Revisada de Valores relativos ao Trabalho (EVT-R). A EVT-R baseou-se na Teoria de Valores Individuais de Schwartz (1999), na Teoria de Valores do Trabalho de Ros, Schwartz e Surkis (1999) e na Escala de Valores relativos ao Trabalho de Porto e Tamayo (2003), formulando-se sobre seis dimensões: Autodeterminação e estimulação (novidade, desafio, pensamento e ação independente); Segurança (estabilidade e independência financeira); Conformidade (compromisso e aceitação de hierarquias, normas e rotinas de trabalho); Universalismo e Benevolência (compreensão, tolerância e proteção do bem-estar dos outros); Realização (sucesso pessoal por competência de acordo com padrões sociais); e Poder (prestígio, status, controle ou domínio sobre pessoas e recursos) (PORTO; PILATI, 2010).

\section{3 ÂNCORAS DE CARREIRA}

A origem do conceito âncora de carreira surgiu nos estudos de Schein ocorridos entre 1961 e 1973, que buscavam compreender a evolução das carreiras e a construção de valores nos indivíduos através das suas organizações empregadoras. Segundo Dutra e Albuquerque (1996), a metáfora da âncora deriva do fato de que as pessoas, ao tentar trabalhos que não lhes parecem adequados, remetem a uma imagem de serem atraídas de volta para alguma coisa onde pensam se encaixar melhor.

Partindo desses fatos, Schein (1996) construiu um inventário que sinaliza oito categorias de inclinação profissional para identificar as âncoras de carreira, determinando a âncora dominante que revela os valores pessoais e incentivando o indivíduo a refletir sobre seus objetivos, valores, áreas de competência ao indicar o seu perfil (SCHEIN, 1996). A Figura 1 mostra as classificações de definições das âncoras de carreira. 


\section{VALORES RELATIVOS AO TRABALHO E ÂNCORAS DE CARREIRA: A ÓTICA DE DISCENTES DO ENSINO SUPERIOR NAS MODALIDADES PRESENCIAL E À DISTÂNCIA \\ DOI: http://dx.doi.org/10.5007/1983-4535.2018v11n1p24}

Figura 1 Âncoras de carreira.

\begin{tabular}{|l|l|}
\hline Âncora de carreira & Definição/características \\
\hline $\begin{array}{l}\text { Autonomia/independência } \\
\text { (AI) }\end{array}$ & $\begin{array}{l}\text { Prioridade à liberdade, autonomia e independência; valorização das } \\
\text { experiências de realização do trabalho cujos ritmos, formas e padrões } \\
\text { são autônomos. }\end{array}$ \\
\hline $\begin{array}{l}\text { Segurança/estabilidade } \\
\text { (SE) }\end{array}$ & $\begin{array}{l}\text { Valorização da estabilidade, da previsibilidade dos níveis de } \\
\text { desempenho e tarefas, das recompensas previsíveis e estáveis. }\end{array}$ \\
\hline $\begin{array}{l}\text { Competência técnica- } \\
\text { funcional (TF) }\end{array}$ & $\begin{array}{l}\text { Valorização de experiências profissionais que vislumbrem a capacidade } \\
\text { técnica individual. }\end{array}$ \\
\hline $\begin{array}{l}\text { Competência gerência } \\
\text { geral (CG) }\end{array}$ & $\begin{array}{l}\text { Prioridade à capacidade analítica na solução de problemas e tomada de } \\
\text { decisões; bom relacionamento interpessoal e intergrupal e ao equilíbrio } \\
\text { emocional. }\end{array}$ \\
\hline $\begin{array}{l}\text { Criatividade } \\
\text { empreendedora (CE) }\end{array}$ & $\begin{array}{l}\text { Criação de novos negócios, produtos ou serviços economicamente } \\
\text { rentáveis; disposição a correr riscos, superar obstáculos para ver o } \\
\text { resultado de seu esforço. }\end{array}$ \\
\hline $\begin{array}{l}\text { Serviço/dedicação a uma } \\
\text { causa (SD) }\end{array}$ & $\begin{array}{l}\text { Prioridade em contribuir para a melhoria da sociedade, tornar o mundo } \\
\text { um lugar melhor, ajudar os outros, solucionar questões ambientais e } \\
\text { sociais. }\end{array}$ \\
\hline Desafio Puro (DP) & $\begin{array}{l}\text { Valorização da superação de obstáculos e solução de problemas } \\
\text { aparentemente insolúveis. }\end{array}$ \\
\hline Estilo de Vida (EV) & $\begin{array}{l}\text { Prioridade ao equilíbrio das esferas pessoal e profissional; percepção de } \\
\text { sucesso relacionada à conquista desse equilíbrio. }\end{array}$ \\
\hline
\end{tabular}

Fonte: elaborado a partir de Schein (1993, 1996); Faro et al.(2010).

Âncoras de carreira tem sido tema frequente em pesquisas científicas da área e o Inventário de Âncoras de Carreira tem sido muito utilizado em estudos internacionais (DANZIGER; RACHMAN-MOORE; VALENCY, 2008; FARO et al., 2010; WILS; WILS; TREMBLAY, 2010; COETZEE; SCHREUDER; 2011). No entanto, em alguns estudos foram evidenciadas distinções quanto aos fatores do modelo proposto por Schein $(1993 ; 1996)$ e ao agrupamento das variáveis, sugerindo a necessidade de novos estudos a fim de aprofundar a temática (WILS; WILS; TREMBLAY, 2010).

Ao se considerar valores, os domínios motivacionais propostos por Schwartz (1992) e as âncoras de carreira propostas por Schein $(1993 ; 1996)$ se sobrepõem, fazendo com que alguns domínios motivacionais estejam diretamente ligados a determinadas âncoras de carreira (WILS; WILS; TREMBLAY, 2010). Baseado nessa sobreposição, Wils, Wils e Tremblay (2010), se fundamentam na correspondência entre os domínios motivacionais dos valores de Schwartz (1992) e as âncoras de carreira propostas por Schein $(1993$; 1996) e propõem um modelo circular de âncoras que considera a dominância de múltiplas carreiras, onde as âncoras e domínios correlacionados positivamente são alocados no mesmo quadrante.

Assim, as âncoras pertencentes ao domínio autotranscendência (competência técnica e serviço/dedicação a uma causa) opõem-se as âncoras pertencentes ao domínio autopromoção 


\section{VALORES RELATIVOS AO TRABALHO E ÂNCORAS DE CARREIRA: A ÓTICA DE DISCENTES DO ENSINO SUPERIOR NAS MODALIDADES PRESENCIAL E À DISTÂNCIA DOI: http://dx.doi.org/10.5007/1983-4535.2018v11n1p24}

(competência gerência geral e Identidade); e as âncoras de abertura à mudança (Desafio puro, criatividade empreendedora e autonomia/independência) opõem-se às âncoras de conservação (estilo de vida, segurança e estabilidade) (WILS; WILS; TREMBLAY, 2010).

É importante considerar que os debates atuais sobre carreira convergem para a interação entre valores individuais, aspirações pessoais e trajetória profissional dos indivíduos (COETZEE e SCHREUDER, 2011; HIRSCHI, 2011). A carreira enfatiza a vida do sujeito e está intimamente ligada aos seus valores e preferências (CHANG et al., 2011), o que destaca a relevância dos valores relativos ao trabalho como antecedentes das decisões sobre carreira.

\section{MODALIDADES DE ENSINO PRESENCIAL E À DISTÂNCIA}

As duas principais modalidades de ensino na educação de nível superior são: presencial e à distância. A modalidade presencial, ou convencional, é a que congrega alunos e professores em um mesmo local e ao mesmo tempo; estes encontros possibilitam a interação direta entre os alunos e entre estes e o professor (PAULSEN, 2002). A modalidade à distância é aquela na qual, por meio de tecnologias de informação e comunicação, os alunos e professores encontram-se distantes geograficamente e não interagem necessariamente ao mesmo tempo, havendo uma interação indireta (ALVES, 2011). Em ambas as modalidades de ensino a aprendizagem acontece, mas de formas distintas, já que cada uma apresenta o conteúdo de uma forma ao aluno e este deve adaptar-se para aprender.

Segundo Paulsen (2002), a modalidade de ensino à distância, baseada na Web, caracteriza-se pela separação física entre o docente e o discente; utilização de uma rede computadorizada para apresentar os conteúdos; e comunicação bidirecional para que os discentes comuniquem-se entre si e com o docente; enquanto que no ensino presencial a interação depende do tempo e do lugar; há contato face a face entre docentes e discentes, uma comunicação síncrona. Devido à questão geográfica, enquanto a modalidade de ensino presencial está focada no ensino unitário, a de educação à distância se preocupa em ensinar o máximo de pessoas no mesmo período de tempo (REIS, 2009).

Algumas vantagens de cada modalidade de ensino são detalhadas por Moran (2000). Para o autor, no ensino presencial o convívio e a troca de experiências por meio de diálogo auxiliam no processo de ensino e podem fornecer os conhecimentos necessários para enfrentar os desafios que surgirão após a conclusão do curso. De outra forma, no ensino à distância, o discente tem a possibilidade de controlar o seu estudo e conciliá-lo com sua 
condição de trabalho ou financeira, não havendo necessidade de contato direto com outras pessoas diariamente, como acontece no ensino presencial.

Aretio (1994) destaca que os discentes do ensino presencial possuem perfis mais homogêneos entre si em relação à idade, qualificação e nível de escolaridade, enquanto que os discentes do ensino à distância tem perfis mais heterogêneos. Também, o autor afirma que os alunos do ensino presencial localizam-se em um único local de estudos possuindo um horário definido (população fixa/local), com a aprendizagem controlada e dependente do professor; e os alunos do ensino à distância estudam em casa ou no local de trabalho, tendo horários flexíveis (população dispersa), caracterizando uma situação livre de aprendizagem e independente do professor. Ainda, no ensino presencial há um maior nível de interação social entre os alunos, enquanto que no ensino à distância este nível de interação social é menor porque os alunos não se encontram face-a-face (ARETIO, 1994).

Compreende-se, enfim, que cada uma das duas modalidades tem suas vantagens e costuma ter um perfil de discentes, cabendo então ao aluno optar pela modalidade que melhor se adapta a sua rotina. Ainda, esta distinção de perfis destacada pela literatura aponta para possíveis diferenças nas percepções em relação aos valores de trabalho e âncoras de carreira entre as duas modalidades de ensino.

\section{MÉTODO}

No intuito de investigar a percepção dos discentes de cursos de graduação presencial e à distância sobre os valores relativos ao trabalho e as âncoras de carreira, foi realizado um estudo descritivo de natureza quantitativa, cuja estratégia de pesquisa utilizada foi uma survey. A população investigada foi composta por discentes de graduação de instituições de ensino superior públicas e privadas do interior do Rio Grande do Sul, pertencentes aos cursos de Administração, Ciências Contábeis, Direito, Educação Física, Serviço Social e Pedagogia.

Foram selecionadas, por conveniência, cinco instituições, sendo que três delas oferecem cursos de graduação na modalidade de ensino presencial e duas delas possuem exclusivamente cursos de graduação na modalidade à distância. A amostra pesquisada perfez um total de 958 discentes, sendo 524 acadêmicos de cursos da modalidade presencial do turno noturno e 434 da modalidade à distância. A Figura 2 apresenta o modelo de pesquisa utilizado nesse trabalho. 
Figura 2 Modelo de pesquisa

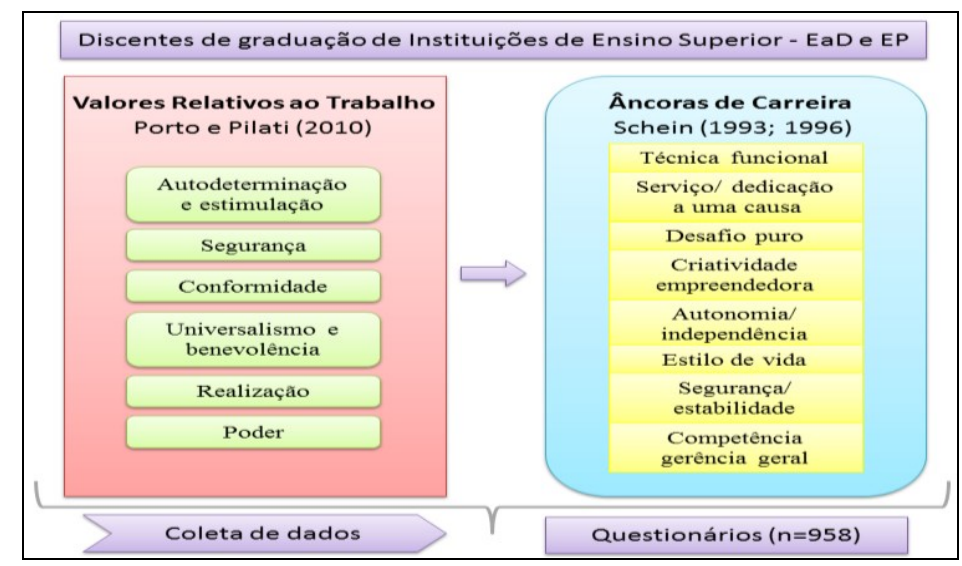

Fonte: elaborado pelos autores

Para fins de coleta dos dados utilizou-se o questionário elaborado a partir de dois modelos. O primeiro refere-se a EVT-R, desenvolvida por Porto e Pilati (2010), composta por 38 questões, distribuídas em seis dimensões, possuindo uma escala tipo likert de 5 pontos, variando de Nada importante (1) a Extremamente importante (5).

O segundo instrumento foi o Inventário de Âncoras de Carreira proposto por Schein (1993; 1996), o qual compreende 40 variáveis, distribuídas em oito dimensões, com uma escala tipo Likert de 6 pontos variando de Nunca se aplica para mim (1) a Sempre se aplica para mim (6). Desta forma, o instrumento final foi composto por 78 questões das escalas acima mencionadas e 15 questões de identificação do perfil individual e profissional dos respondentes.

Após coletados, os dados foram analisados com o apoio do software SPSS (Statistical Package for the Social Sciences) para realização dos testes estatísticos.

\section{ANÁLISE DOS RESULTADOS}

\subsection{ANÁLISE DESCRITIVA DA AMOSTRA}

Em relação à amostra investigada, foram entrevistados 958 discentes de graduação de instituições de ensino superior, sendo 337 discentes de cursos na modalidade presencial de instituições privadas, 187 de cursos na modalidade presencial de instituições públicas e 434 de cursos na modalidade a distância de instituições privadas. A Tabela 1 apresenta o perfil dos entrevistados e a significância do Qui-Quadrado. 
Tabela 1 Perfil dos entrevistados nas modalidades de ensino presencial e a distância e teste QuiQuadrado

\begin{tabular}{|c|c|c|c|c|c|c|c|}
\hline \multirow{2}{*}{ Variáveis } & \multirow{2}{*}{ Entrevistados } & \multicolumn{2}{|c|}{$\begin{array}{l}\text { Modalidade } \\
\text { presencial }(n=524)\end{array}$} & \multicolumn{2}{|c|}{$\begin{array}{l}\text { Modalidade } \\
\text { a distância }(n=434)\end{array}$} & \multirow{2}{*}{$\begin{array}{l}\text { Total } \\
\%\end{array}$} & \multirow{2}{*}{$\frac{\chi^{2}}{\text { Sig }}$} \\
\hline & & $\begin{array}{l}\text { Frequênci } \\
\text { a }\end{array}$ & $\%$ & Frequência & $\%$ & & \\
\hline \multirow{5}{*}{ Idade } & 16 a 21 anos & 194 & 37,3 & 79 & 18,4 & 28,7 & \multirow{5}{*}{$\begin{array}{l}0,00 \\
0\end{array}$} \\
\hline & 22 a 25 anos & 168 & 32,3 & 104 & 24,2 & 28,6 & \\
\hline & 26 a 30 anos & 98 & 18,8 & 102 & 23,7 & 21,1 & \\
\hline & 31 a 40 anos & 42 & 8,1 & 105 & 24,4 & 15,5 & \\
\hline & 41 a 62 anos & 18 & 3,5 & 40 & 9,3 & 6,1 & \\
\hline \multirow{2}{*}{ Sexo } & Homens & 263 & 50,3 & 138 & 32,2 & 42,1 & \multirow{2}{*}{$\begin{array}{l}0,00 \\
0\end{array}$} \\
\hline & Mulheres & 260 & 49,7 & 291 & 67,8 & 57,9 & \\
\hline \multirow{5}{*}{ Estado civil } & Solteiro & 422 & 80,8 & 213 & 50,1 & 67,1 & \multirow{5}{*}{$\begin{array}{l}0,00 \\
0\end{array}$} \\
\hline & Casado & 60 & 11,5 & 135 & 31,8 & 20,6 & \\
\hline & Divorciado & 4 & 0,8 & 21 & 4,9 & 2,6 & \\
\hline & Viúvo & 1 & 0,2 & 0 & - & 0,1 & \\
\hline & União Estável & 35 & 6,7 & 56 & 13,2 & 9,6 & \\
\hline \multirow{2}{*}{$\begin{array}{l}\text { Experiência } \\
\text { profissional }\end{array}$} & Sim & 413 & 79,6 & 354 & 84,3 & 81,7 & \multirow{2}{*}{$\begin{array}{l}0,03 \\
8\end{array}$} \\
\hline & Não & 106 & 20,4 & 66 & 15,7 & 18,3 & \\
\hline \multirow{2}{*}{$\begin{array}{l}\text { Trabalha } \\
\text { atualmente }\end{array}$} & Sim & 346 & 66,4 & 324 & 76,6 & 71,0 & \multirow{2}{*}{$\begin{array}{l}0,00 \\
0\end{array}$} \\
\hline & Não & 175 & 33,6 & 99 & 23,4 & 29,0 & \\
\hline
\end{tabular}

Fonte: Dados da pesquisa

A partir da aplicação do teste Qui-Quadrado $\left(\chi^{2}\right)$ foi possível avaliar a relação entre as variáveis de perfil e as modalidades de ensino (presencial e à distância). Com 95\% de confiança, o teste foi significativo para as variáveis: Idade, Sexo, Estado Civil, Experiência Profissional e Trabalha atualmente, indicando que há diferença entre os alunos das duas modalidades.

Em relação à idade, na modalidade presencial predominou respondentes entre 16 e 21 anos $(37,3 \%)$ e na modalidade à distância predominou entre 31 e 40 anos $(24,4 \%)$, confirmando a afirmação de Gilbert (2001), de que o discente do ensino à distância costuma ter mais de 25 anos; e de Ferlin e Tozzi (2005), de que o discente da modalidade presencial é geralmente mais jovem. Quanto ao sexo, a predominância foi de 50,3\% de homens na modalidade presencial e 67,8\% de mulheres na modalidade à distância.

Sobre o estado civil dos mesmos, predominaram os solteiros, havendo diferença estatisticamente significativa entre as modalidades de ensino (80,8\% na modalidade presencial e 50,1\% na modalidade à distância). Observa-se que não se destaca a homogeneidade nos dados relacionados à modalidade presencial, conforme sugerido por Aretio (1994), provavelmente devido à amostra pesquisada ser do turno noturno. 
Quanto à experiência profissional, 79,6\% dos entrevistados da modalidade presencial e $84,3 \%$ do ensino à distância já exerceram alguma atividade laboral; ainda, 66,4\% da modalidade presencial e $76,6 \%$ da modalidade à distância estão trabalhando atualmente, havendo diferença estatisticamente significativa entre as modalidades de ensino. Tais dados corroboram as afirmações de Gilbert (2001), de que o discente do ensino à distância costuma trabalhar; e de Ferlin e Tozzi (2005), de que o discente do ensino presencial neste caso geralmente trabalha e estuda, tendo ingressado precocemente no mercado de trabalho, explicado pelo fato de $79,6 \%$ já terem exercido alguma atividade laboral e atualmente apenas $66,4 \%$ estarem trabalhando. A Tabela 2 demonstra o perfil das atividades profissionais exercidas por esses indivíduos.

Tabela 2 Perfil das atividades profissionais dos entrevistados nas modalidades de ensino presencial e a distância e teste Qui-Quadrado

\begin{tabular}{|c|c|c|c|c|c|c|c|}
\hline \multirow{2}{*}{ Variáveis } & \multirow{2}{*}{ Entrevistados } & \multicolumn{2}{|c|}{$\begin{array}{l}\text { Modalidade } \\
\text { presencial }(n=524)\end{array}$} & \multicolumn{2}{|c|}{$\begin{array}{l}\text { Modalidade à } \\
\text { distância }(n=434)\end{array}$} & \multirow{2}{*}{$\begin{array}{l}\text { Total } \\
\%\end{array}$} & \multirow{2}{*}{$\begin{array}{l}\chi^{2} \\
\text { Sig }\end{array}$} \\
\hline & & Frequência & $\%$ & Frequência & $\%$ & & \\
\hline \multirow{5}{*}{$\begin{array}{lr}\text { Empresa } & \text { onde } \\
\text { trabalha } & \\
\text { (setor/ramo } & \text { de } \\
\text { atuação) } & \end{array}$} & Serviços & 88 & 26,1 & 69 & 22,5 & 24,4 & \multirow{5}{*}{0.000} \\
\hline & Comércio & 53 & 15,7 & 97 & 31,7 & 23,3 & \\
\hline & Indústria & 6 & 1,8 & 5 & 1,6 & 1,7 & \\
\hline & Pública & 97 & 28,8 & 67 & 21,9 & 25,5 & \\
\hline & \begin{tabular}{|l|} 
Outros \\
\end{tabular} & 93 & 27,6 & 68 & 22,2 & 25,0 & \\
\hline \multirow{10}{*}{ Cargo ocupado } & Gerente /diretor & 36 & 11,1 & 38 & 10,2 & 11,8 & \multirow{10}{*}{0.000} \\
\hline & $\begin{array}{l}\text { Coordenador, } \\
\text { supervisor e fiscal }\end{array}$ & 34 & 10,5 & 24 & 6,4 & 9,2 & \\
\hline & Professor & 16 & 4,9 & 18 & 4,8 & 5,4 & \\
\hline & Vendedor & 13 & 4,0 & 37 & 9,9 & 8,0 & \\
\hline & $\begin{array}{l}\text { Auxiliar e assist. } \\
\text { adm. e caixa }\end{array}$ & 74 & 22,8 & 61 & 16,3 & 21,5 & \\
\hline & $\begin{array}{l}\text { Secretária } \\
\text { atendente }\end{array}$ & 27 & 8,3 & 40 & 10,7 & 10,7 & \\
\hline & $\begin{array}{l}\text { Técnico } \\
\text { (radiologia, } \\
\text { contábil, etc) }\end{array}$ & 10 & 3,1 & 21 & 5,6 & 4,9 & \\
\hline & $\begin{array}{l}\text { Cargos } \\
\text { operacionais }\end{array}$ & 12 & 3,7 & 32 & 8,6 & 7,0 & \\
\hline & Militar & 25 & 7,7 & 25 & 6,7 & 6,2 & \\
\hline & \begin{tabular}{|l} 
Outros \\
\end{tabular} & 78 & 24,0 & 78 & 20,9 & 15,3 & \\
\hline
\end{tabular}

Fonte: Dados da pesquisa

Quanto ao setor de atuação da empresa onde trabalham, 28,8\% dos discentes da modalidade presencial atuam em instituições públicas e 31,7\% da modalidade à distância no comércio, havendo diferença estatisticamente significativa entre as modalidades. 


\section{VALORES RELATIVOS AO TRABALHO E ÂNCORAS DE CARREIRA: A ÓTICA DE DISCENTES DO ENSINO SUPERIOR NAS MODALIDADES PRESENCIAL E À DISTÂNCIA DOI: http://dx.doi.org/10.5007/1983-4535.2018v11n1p24}

Em relação ao cargo ocupado na empresa, 21,5\% dos respondentes são auxiliares/assistentes administrativos/caixa $(22,8 \%$ na modalidade presencial e $16, \%$ na modalidade à distância), havendo diferença estatisticamente significativa entre as duas modalidades.

\subsection{ANÁLISE DOS FATORES RELATIVOS AO TRABALHO E ÂNCORAS DE CARREIRA}

Para a análise fatorial das variáveis da EVT-R e do Inventário de Âncoras de Carreira, foram utilizadas, inicialmente, as 38 questões do instrumento EVT-R e as 40 questões do Inventário de Âncoras de Carreira, com o intuito de identificar possíveis associações entre as variáveis, de modo a agrupá-las em fatores comuns.

Optou-se por adotar a análise de componentes principais como método de extração das dimensões e a Varimax como método de rotação. Os testes iniciais da fatorial incluíram o Kaiser-Meyer-Olkin Measure of Sampling Adequacy (KMO) e o teste de esfericidade de Bartlett. Assim, os resultados dos testes de adequação e especificidade da amostra foram satisfatórios - no EVT-R, o KMO apresentou um coeficiente de 0,911 e o teste de Bartlett apresentou resultado significativo (sig 0,000); e no Inventário de Âncoras de Carreira, o KMO apresentou coeficiente de 0,906 e o teste de Bartlett apresentou resultado significativo (sig 0,000). Além disso, as análises de medida para adequação da amostra e da matriz correlação anti-imagem, também, foram satisfatórias para análise fatorial.

Em seguida, foram analisadas as comunalidades, onde percebeu-se que oito variáveis do EVT-R e doze variáveis do Inventário de Âncoras de Carreira apresentaram valor inferior a 0,5 , sendo excluídas das etapas subsequentes. Então, na etapa de extração dos fatores utilizaram-se os critérios dos autovalores (eingenvalues) maiores que 1,0 e porcentagem da variância explicada. No EVT-R foram obtidos oito fatores com autovalores superiores a 1,0, sendo que o primeiro explicou $27,04 \%$ da variância e os outros explicaram, em conjunto, $64,10 \%$ de toda variância e no Inventário das Âncoras de Carreira foram obtidos sete fatores com autovalores superiores a 1,0, que explicaram, em conjunto, $61,70 \%$ de toda variância. Ao analisar a confiabilidade, conforme o teste Alfa de Cronbach, excluiu-se um fator do modelo EVT-R (Conformidade) e um fator do Inventário de Âncoras de Carreira (Competência Técnica-funcional), os quais apresentaram valores insatisfatórios (inferiores a 0,6 ).

Uma análise mais detalhada permite avaliar as variáveis componentes de cada fator, de maneira que os fatores criados refletem, em sua maioria, a predominância de determinada 


\section{VALORES RELATIVOS AO TRABALHO E ÂNCORAS DE CARREIRA: A ÓTICA DE DISCENTES DO ENSINO SUPERIOR NAS MODALIDADES PRESENCIAL E À DISTÂNCIA DOI: http://dx.doi.org/10.5007/1983-4535.2018v11n1p24}

dimensão de Valores Relativos ao Trabalho (Tabela 3) e de Âncoras de Carreira (Tabela 4) identificados no modelo original desenvolvido por Porto e Pilati (2010) e Schein (1993; 1996), respectivamente.

Tabela 3 Fatorial Valores do trabalho

\begin{tabular}{|c|c|c|}
\hline Variáveis & Fator original & \begin{tabular}{|l|} 
Carga \\
Fatoria \\
1 \\
\end{tabular} \\
\hline \multicolumn{3}{|l|}{ Fator 1 - Realização - Alfa 0,832} \\
\hline $\begin{array}{l}\text { 16. Ser reconhecido pelo resultado satisfatório do meu } \\
\text { trabalho }\end{array}$ & Realização & 0,766 \\
\hline 17. Ser respeitado pelas minhas competências no trabalho & Realização & 0,749 \\
\hline 13. Ser admirado pelo meu trabalho & Realização & 0,720 \\
\hline 14. Ser bem-sucedido na minha profissão & Realização & 0,589 \\
\hline 4. Demonstrar minhas competências & Realização & 0,556 \\
\hline $\begin{array}{l}\text { 35. Ter um trabalho que me permita expressar meus } \\
\text { conhecimentos }\end{array}$ & $\begin{array}{l}\text { Autodeterminação } \\
\text { estimulação }\end{array}$ & 0,459 \\
\hline \multicolumn{3}{|l|}{ Fator 2 - Segurança - Alfa 0,785} \\
\hline 6. Obter estabilidade financeira & Segurança & 0,770 \\
\hline 11. Poder me sustentar financeiramente & Segurança & 0,747 \\
\hline 15. Ser independente financeiramente & Segurança & 0,732 \\
\hline 8. Ganhar dinheiro & Segurança & 0,686 \\
\hline \multicolumn{3}{|l|}{ Fator 3 - Estimulação Alfa 0,777} \\
\hline 30. Ter um trabalho criativo & \begin{tabular}{|l|} 
Autodeterminação \\
estimulação
\end{tabular} & 0,760 \\
\hline 31. Ter um trabalho inovador & $\begin{array}{l}\text { Autodeterminação } \\
\text { estimulação }\end{array}$ & 0,741 \\
\hline 22. Ter desafios constantes & $\begin{array}{l}\text { Autodeterminação } \\
\text { estimulação }\end{array}$ & 0,554 \\
\hline 7. Estimular a minha curiosidade & $\begin{array}{l}\text { Autodeterminação } \\
\text { estimulação }\end{array}$ & 0,529 \\
\hline 5. Desenvolver novas habilidades & $\begin{array}{l}\text { Autodeterminação } \\
\text { estimulação }\end{array}$ & 0,466 \\
\hline \multicolumn{3}{|l|}{ Fator 4 - Universalismo e benevolência Alfa 0,765} \\
\hline 2. Colaborar para o desenvolvimento da sociedade & Universalismo e benevolência & 0,829 \\
\hline 3. Combater injustiças sociais & Universalismo e benevolência & 0,793 \\
\hline 1. Ajudar os outros & Universalismo e benevolência & 0,703 \\
\hline \multicolumn{3}{|l|}{ Fator 5 - Poder Alfa 0,744} \\
\hline 23. Ter fama & Poder & 0,766 \\
\hline 26. Ter prestígio & Poder & 0,597 \\
\hline 28. Ter um trabalho arriscado & $\begin{array}{l}\text { Autodeterminação } \\
\text { estimulação }\end{array}$ & 0,589 \\
\hline 19. Supervisionar outras pessoas & Poder & 0,588 \\
\hline \multicolumn{3}{|l|}{ Fator 6 - Autodeterminação Alfa 0,773} \\
\hline $\begin{array}{l}\text { 34. Ter um trabalho que me permita conhecer pessoas } \\
\text { novas }\end{array}$ & $\begin{array}{l}\text { Autodeterminação } \\
\text { estimulação }\end{array}$ & 0,746 \\
\hline $\begin{array}{l}\text { 33. Ter um trabalho que me permita conhecer lugares } \\
\text { novos }\end{array}$ & $\begin{array}{l}\text { Autodeterminação } \\
\text { estimulação }\end{array}$ & 0,728 \\
\hline
\end{tabular}




\begin{tabular}{l|lrl}
\hline 36. Ter um trabalho que requer originalidade & $\begin{array}{l}\text { Autodeterminação } \\
\text { estimulação }\end{array}$ & $\mathrm{e}$ & 0,501 \\
\hline 37. Ter uma profissão reconhecida socialmente & Poder & 0,477 \\
\hline Fator 7 - Autonomia Alfa 0,719 & \multicolumn{2}{|l}{} \\
\hline 20. Ter autonomia na realização das minhas tarefas & $\begin{array}{l}\text { Autodeterminação } \\
\text { estimulação }\end{array}$ & 0,637 \\
\hline 24. Ter liberdade para decidir como realizar meu trabalho & $\begin{array}{l}\text { Autodeterminação } \\
\text { estimulação }\end{array}$ & $\mathrm{e}$ & 0,570 \\
\hline 18. Ser útil para a sociedade & Universalismo e benevolência & 0,477 \\
\hline 21. Ter compromisso social & Universalismo e benevolência & 0,472 \\
\hline
\end{tabular}

Fonte: Dados da pesquisa

Conforme é possível visualizar na Tabela 3, no Fator 01 estão associadas cinco variáveis relacionadas à Realização e uma originalmente relacionada à Autodeterminação e Estimulação. Isso pode estar relacionado ao fato de que ter um trabalho que permita expressar os conhecimentos, além de proporcionar estímulo e autodeterminação, também pode ser considerado um aspecto importante de realização no trabalho, referindo-se a estimulação, independência de pensamento e ação no trabalho por meio da autonomia (PORTO; TAMAYO, 2003).

O Fator 02 contém quatro variáveis relacionadas à Segurança que, segundo Porto e Pilati (2010), corresponde à independência financeira, estabilidade e sentir-se seguro no trabalho. O Fator 03 possui cinco variáveis relacionadas à Autodeterminação e Estimulação. Conforme Porto e Tamayo (2003), a Autodeterminação e Estimulação referem-se ao pensamento e ações independentes e ao enfrentamento de desafios e novidades. O Fator 04 contém três variáveis relacionadas ao Universalismo e Benevolência, que dizem respeito ao senso comum, envolvendo tolerância, compreensão e proteção do bem-estar dos outros (PORTO, PILATI, 2010).

No Fator 05 encontram-se três variáveis relacionadas a Poder e uma relacionada à Autodeterminação e Estimulação. Enquanto o Poder está relacionado ao status, prestígio e domínio sobre pessoas e recursos (PORTO; PILATI, 2010), a Autodeterminação e Estimulação pode ter se agrupado ao fator por relacionar poder à capacidade de um indivíduo em realizar um trabalho arriscado. O Fator 06 contém três variáveis relacionadas à Autodeterminação e Estimulação e uma relacionada a Poder. Da mesma forma que no Fator 05, percebe-se que há certa percepção de proximidade entre as variáveis dos fatores Autodeterminação e Estimulação e Poder, fazendo com que se agrupem em um mesmo fator. 


\section{VALORES RELATIVOS AO TRABALHO E ÂNCORAS DE CARREIRA: A ÓTICA DE DISCENTES DO ENSINO SUPERIOR NAS MODALIDADES PRESENCIAL E À DISTÂNCIA DOI: http://dx.doi.org/10.5007/1983-4535.2018v11n1p24}

Por fim, o Fator 07 possui duas variáveis relacionadas à Autodeterminação e Estimulação e duas relacionadas a Universalismo e Benevolência. $\mathrm{O}$ agrupamento destas variáveis em um mesmo fator pode estar relacionado ao fato de que o indivíduo com maior autonomia e liberdade para realizar seu trabalho, também pode usar essa autonomia e liberdade em prol de causas sociais que beneficiem a sociedade.

Os fatores finais obtidos foram: Segurança, com quatro variáveis associadas a maior média entre os fatores $(4,4)$; Poder, com quatro variáveis e menor média entre os fatores $(2,7)$; Realização, com seis variáveis e média de 4,2; Universalismo e Benevolência, contendo três variáveis com média de 4,0; Autonomia, com quatro variáveis e média de 3,9; Estimulação, com cinco itens e média de 3,8; e Autodeterminação, com quatro itens com média de 3,5.

Em relação ao Inventário de Âncoras de Carreira, evidenciou-se distinções acerca do agrupamento das variáveis e dos fatores deste modelo (DANZIGER; RACHMAN-MOORE; VALENCY, 2008), sugerindo a necessidade de novos estudos que visem confirmar a estrutura dos fatores propostos. Assim, constata-se a importância de identificar as dimensões que compõem as âncoras de carreira na perspectiva dos discentes do ensino superior. Conforme é possível visualizar, a Tabela 4 aponta os agrupamentos das variáveis e seus fatores originais com as cargas fatoriais correspondentes.

Tabela 4 Fatorial Âncoras de Carreira

\begin{tabular}{l|c|c}
\hline \multicolumn{1}{c|}{ Variáveis } & Fator original & $\begin{array}{c}\text { Carga } \\
\text { Fatorial }\end{array}$ \\
\hline \multicolumn{1}{c|}{ Fator 1 - Gerência geral - Alfa 0,854 } \\
\hline $\begin{array}{l}\text { 34. Prefiro deixar meu emprego do que aceitar atribuições que me } \\
\text { afastem da trajetória de exercer uma função de gerência geral }\end{array}$ & Gerencia geral & 0,760 \\
\hline $\begin{array}{l}\text { 35. Prefiro sair de meu emprego a aceitar atribuições que reduzam a } \\
\text { minha autonomia e liberdade }\end{array}$ & Autonomia/independência & 0,683 \\
\hline $\begin{array}{l}\text { 25. Prefiro deixar meu emprego do que aceitar uma tarefa de rodízio } \\
\text { que me afaste da minha área de especialidade }\end{array}$ & Técnica funcional & 0,675 \\
\hline $\begin{array}{l}\text { 18. Somente vou achar que minha carreira é um sucesso se ocupar o } \\
\text { cargo de gerente geral em alguma empresa }\end{array}$ & Gerência geral & 0,618 \\
\hline $\begin{array}{l}\text { 26. Tornar-me um gerente geral é mais atraente para mim do que } \\
\text { tornar-me um gerente técnico em minha área de especialização }\end{array}$ & Gerência geral & 0,603 \\
\hline $\begin{array}{l}\text { 27. Considero mais importante a oportunidade de realizar o trabalho } \\
\text { a meu modo, livre de regras e pressões do que ter segurança }\end{array}$ & Autonomia/independência & 0,584 \\
\hline $\begin{array}{l}\text { 38. Prefiro deixar meu emprego a aceitar atribuições que } \\
\text { prejudiquem minha habilidade de ser útil aos outros }\end{array}$ & $\begin{array}{c}\text { Serviço/dedicação a uma } \\
\text { causa }\end{array}$ & 0,531 \\
\hline $\begin{array}{l}\text { 29. Somente vou achar que minha carreira é um sucesso se conseguir } \\
\text { criar ou construir algo que seja uma produção ou ideia inteiramente } \\
\text { minha }\end{array}$ & $\begin{array}{c}\text { Criatividade } \\
\text { empreendedora }\end{array}$ & 0,445 \\
\hline \multicolumn{2}{c}{ Fator 2 - Serviço/dedicação a uma causa Alfa 0,788} & \\
\hline
\end{tabular}




\section{VALORES RELATIVOS AO TRABALHO E ÂNCORAS DE CARREIRA: A ÓTICA DE DISCENTES DO ENSINO SUPERIOR NAS MODALIDADES PRESENCIAL E À DISTÂNCIA DOI: http://dx.doi.org/10.5007/1983-4535.2018v11n1p24}

\begin{tabular}{l|c|c}
\hline $\begin{array}{l}\text { 6. Somente considerarei minha carreira um sucesso se achar que } \\
\text { contribuí verdadeiramente para o bem-estar da sociedade }\end{array}$ & $\begin{array}{c}\text { Serviço/dedicação a uma } \\
\text { causa }\end{array}$ & 0,764 \\
\hline $\begin{array}{l}\text { 30. Sonho em ter uma carreira que dê uma contribuição para a } \\
\text { humanidade e a sociedade }\end{array}$ & $\begin{array}{c}\text { Serviço/dedicação a uma } \\
\text { causa }\end{array}$ & 0,748 \\
\hline $\begin{array}{l}\text { 22. Acho mais importante utilizar minhas aptidões para fazer deste } \\
\text { mundo um lugar melhor do que alcançar uma posição gerencial de } \\
\text { alto nível }\end{array}$ & $\begin{array}{c}\text { Serviço/dedicação a uma } \\
\text { causa }\end{array}$ & 0,741 \\
\hline $\begin{array}{l}\text { 39. Acho mais importante solucionar problemas quase insolúveis do } \\
\text { que alcançar uma posição gerencial de alto nível }\end{array}$ & Desafio puro & 0,486 \\
\hline $\begin{array}{l}\text { 7. Sonho com uma carreira que me possibilite solucionar problemas } \\
\text { ou vencer em situações desafiadoras }\end{array}$ & Desafio puro & 0,474 \\
\hline
\end{tabular}

Fator 3 - Segurança e estabilidade Alfa 0,768

\begin{tabular}{l|l|l}
\hline $\begin{array}{l}\text { 36. Sonho em seguir uma carreira que me permita sentir segurança e } \\
\text { assegure estabilidade }\end{array}$ & Segurança/estabilidade & 0,820 \\
\hline $\begin{array}{l}\text { 28. Sinto-me mais realizado em meu trabalho quando acho que tenho } \\
\text { inteira segurança financeira e estabilidade }\end{array}$ & Segurança/estabilidade & 0,756 \\
\hline $\begin{array}{l}\text { 20. Procuro trabalhos em empresas que me dêem sensação de } \\
\text { segurança e estabilidade }\end{array}$ & Segurança/estabilidade & 0,753 \\
\hline $\begin{array}{l}\text { 4. Considero segurança e estabilidade mais importantes para mim do } \\
\text { que liberdade e autonomia }\end{array}$ & Segurança/estabilidade & 0,658 \\
\hline
\end{tabular}

Fator 4 - Criatividade empreendedora Alfa 0,815

37. Sonho em iniciar e fazer crescer meu próprio empreendimento

5. Estou sempre à procura de ideias que me permitam dar início a um empreendimento próprio

13. Acho mais importante ter meu próprio negócio do que atingir uma alta posição gerencial como empregado

Fator 5 - Desafio puro Alfa 0,733

33. Sinto-me mais realizado em meu trabalho quando sou capaz de utilizar minhas aptidões e talentos

24. Somente acho que minha vida está sendo bem-sucedida quando consigo contrabalançar exigências pessoais, familiares e profissionais

23. Sinto-me mais realizado em relação à minha carreira quando resolvo problemas aparentemente insolúveis ou venço em situações muito adversas

31. Procuro oportunidades profissionais que desafiem minha capacidade de solucionar problemas

\begin{tabular}{c|c}
\hline $\begin{array}{c}\text { Criatividade } \\
\text { empreendedora }\end{array}$ & 0,838 \\
\hline $\begin{array}{c}\text { Criatividade } \\
\text { empreendedora }\end{array}$ & 0,771 \\
\hline $\begin{array}{c}\text { Criatividade } \\
\text { empreendedora }\end{array}$ & 0,70 \\
\hline
\end{tabular}

Fator 6 - Autonomia e independência Alfa 0,752

3. Sonho em ter uma carreira que me dê a liberdade de executar meu trabalho a meu modo e dentro do meu horário.

11. Sinto-me mais realizado em meu trabalho quando tenho inteira liberdade de definir minhas tarefas, horários e métodos

16. Sonho com uma carreira que me permita conciliar minhas necessidades pessoais, familiares e profissionais

19. Somente vou achar que minha carreira é um sucesso se conseguir total autonomia e liberdade

\begin{tabular}{|c|c}
\hline Autonomia/independência & 0,754 \\
\hline Autonomia/independência & 0,730 \\
\hline Estilo de vida & 0,513 \\
\hline Autonomia/independência & 0,509 \\
\hline
\end{tabular}

Fonte: Dados da pesquisa 


\section{VALORES RELATIVOS AO TRABALHO E ÂNCORAS DE CARREIRA: A ÓTICA DE DISCENTES DO ENSINO SUPERIOR NAS MODALIDADES PRESENCIAL E À DISTÂNCIA DOI: http://dx.doi.org/10.5007/1983-4535.2018v11n1p24}

De acordo com a Tabela 4, no Fator 01, têm-se três variáveis relacionadas à Gerência Geral, duas relacionadas à Autonomia/Independência, uma à Técnica Funcional, uma a Serviço/Dedicação a uma causa e uma à Criatividade Empreendedora. Segundo Coetzee, Schreuder e Tladinyane (2007), a competência Gerência Geral está relacionada a um trabalho desafiador, oportunidades de liderança e desejo de altos salários, ligados a promoções, mérito ou resultados, aspectos que parecem também estar relacionados às variáveis citadas na Autonomia/independência e Criatividade Empreendedora. A Técnica Funcional está ligada a oportunidades e desenvolvimento profissional, o que talvez justifique a sua alocação para os Fatores 01 (Gerência Geral) e 05 (Desafio Puro). Por fim, a âncora Serviço/Dedicação a uma causa refere-se à satisfação em contribuir para a melhoria da sociedade, ajudando os outros e solucionando questões ambientais e sociais (SCHEIN, 1993, 1996; FARO et al., 2010).

O Fator 02 possui três variáveis que abordam Serviço/Dedicação a uma causa e duas variáveis que abordam Desafio puro. O agrupamento dessas variáveis de fatores distintos em um mesmo fator pode estar relacionado ao fato de que todas as variáveis associadas dizem respeito ao desafio em solucionar problemas, seja no âmbito profissional quanto em questões sociais ou ambientais.

O Fator 03 possui quatro variáveis referentes ao fator Segurança/Estabilidade. A principal preocupação nessa âncora é a baixa volatilidade da carreira e a sensação de bemgerada por isso. O profissional aqui ancorado irá valorizar a estabilidade e a previsibilidade dos desempenhos, tarefas e recompensas (SCHEIN, 1993; FARO et al., 2010).

O Fator 04 inclui três variáveis referentes à Criatividade Empreendedora. Segundo Schein (1993) e Faro et al. (2010), a Criatividade Empreendedora diz respeito à criação de negócios economicamente rentáveis, disposição a correr riscos e superar obstáculos.

O Fator 05 possui duas variáveis relacionadas a Desafio Puro, uma relacionada à Técnica Funcional e uma relacionada a Estilo de vida. A associação de quatro variáveis de diferentes fatores num outro fator pode estar relacionada ao fato de que a percepção de realização e sucesso profíssional está vinculada à utilização de aptidões e talentos em situações desafiadoras e adversas, mas também a conseguir contrabalançar exigências pessoais, familiares e profissionais.

O Fator 06 tem três variáveis relacionadas à Autonomia/Independência e uma a Estilo de vida. As âncoras Autonomia/Independência e Estilo de Vida aparecem agrupadas, pois conforme Schein (1993), a Autonomia/Independência está associada à prioridade a liberdade 


\section{VALORES RELATIVOS AO TRABALHO E ÂNCORAS DE CARREIRA: A ÓTICA DE DISCENTES DO ENSINO SUPERIOR NAS MODALIDADES PRESENCIAL E À DISTÂNCIA DOI: http://dx.doi.org/10.5007/1983-4535.2018v11n1p24}

e autonomia, valorizando ritmos, formas e padrões de trabalho autônomos e a variável que representa o Estilo de Vida nesse agrupamento diz respeito justamente à possibilidade de uma carreira que permita conciliar necessidades pessoais, familiares e profissionais.

Assim, os fatores finais obtidos foram: Desafio Puro (média 4,4); Segurança e Estabilidade (média 4,3); Autonomia e Independência (média 4,2); Serviço/Dedicação a uma Causa (média 3,9); Criatividade Empreendedora (média 3,6); e Gerência Geral (média 3,1).

\subsection{VALORES RELATIVOS AO TRABALHO E ÂNCORAS DE CARREIRA}

A partir da composição dos fatores dos Valores Relativos ao Trabalho e das Âncoras de Carreira, buscou-se comparar as médias entre as duas modalidades de ensino, visando identificar discrepâncias relacionadas à natureza das modalidades à distância e presencial, por meio do teste $t$ para amostras independentes.

Previamente à aplicação do teste t, realizou-se o teste F para avaliar a igualdade das variâncias, visando decidir se o teste $\mathrm{t}$ deveria ser homocedástico ou heterocedástico. Observou-se que as dimensões Segurança, Estimulação, Universalismo e Benevolência, Poder, Autodeterminação e Autonomia dos Valores Relativos ao trabalho e as dimensões Gerência Geral, Serviço/Dedicação a uma Causa, Criatividade Empreendedora e Autonomia/Independência das Âncoras de Carreira apresentaram diferenças significativas de médias. Para ambos, percebeu-se diferença entre os dois tipos de modalidade, como demonstra a Tabela 5 .

Tabela 5 Teste de Diferença de Média para os Fatores dos Valores do Trabalho e Âncoras de carreira

\begin{tabular}{l|c|c|c|c|c|c}
\hline \multirow{2}{*}{$\begin{array}{c}\text { Dimensões dos Valores do } \\
\text { Trabalho }\end{array}$} & \multicolumn{2}{c|}{$\begin{array}{c}\text { Modalidade } \\
\text { Presencial }\end{array}$} & \multicolumn{2}{c}{$\begin{array}{c}\text { Modalidade à } \\
\text { distância }\end{array}$} & \multicolumn{2}{c}{ Teste T } \\
\cline { 2 - 7 } & Média & Desvio & Média & Desvio & $\begin{array}{c}\text { Valo } \\
\text { r }\end{array}$ & Sig \\
\hline Realização & 4,25 & 0,58 & 4,28 & 0,58 & 0,57 & $\begin{array}{c}0,56 \\
8\end{array}$ \\
\hline Segurança & 4,44 & 0,57 & 4,36 & 0,59 & 2,02 & $\begin{array}{c}0,04 \\
3\end{array}$ \\
\hline Estimulação & 3,80 & 0,64 & 3,97 & 0,61 & 4,18 & $\begin{array}{c}0,00 \\
0\end{array}$ \\
\hline Universalismo e benevolência & 3,91 & 0,71 & 4,18 & 0,70 & 5,83 & $\begin{array}{c}0,00 \\
0\end{array}$ \\
\hline Poder & 2,65 & 0,72 & 2,88 & 0,95 & 4,14 & $\begin{array}{c}0,00 \\
0\end{array}$ \\
\hline Autodeterminação & 3,45 & 0,77 & 3,74 & 0,79 & 5,57 & $\begin{array}{c}0,00 \\
0\end{array}$ \\
\hline Autonomia & 3,81 & 0,61 & 4,00 & 0,62 & 4,82 & 0,00 \\
\hline
\end{tabular}




\begin{tabular}{l|c|c|c|c|c|c}
\hline \multicolumn{1}{c|}{$\begin{array}{c}\text { Dimensões das Âncoras de } \\
\text { Carreira }\end{array}$} & Média & Desvio & Média & Desvio & $\begin{array}{c}\text { Valo } \\
\text { r }\end{array}$ & Sig \\
\hline Gerência Geral & 3,05 & 0,95 & 3,30 & 1,29 & 3,46 & $\begin{array}{c}0,00 \\
1\end{array}$ \\
\hline Serviço/dedicação a uma causa & 3,80 & 1,06 & 4,21 & 1,07 & 5,90 & $\begin{array}{c}0,00 \\
0\end{array}$ \\
\hline Segurança e estabilidade & 4,29 & 1,11 & 4,36 & 1,08 & 0,87 & $\begin{array}{c}0,38 \\
4\end{array}$ \\
\hline Criatividade empreendedora & 3,51 & 1,47 & 3,80 & 1,45 & 3,09 & $\begin{array}{c}0,00 \\
2\end{array}$ \\
\hline Desafio puro & 4,50 & 0,93 & 4,48 & 1,03 & 0,18 & $\begin{array}{c}0,85 \\
6\end{array}$ \\
\hline Autonomia/independência & 4,35 & 1,06 & 4,13 & 1,19 & 2,98 & $\begin{array}{c}0,00 \\
3\end{array}$ \\
\hline
\end{tabular}

Fonte: Dados da pesquisa

Conforme é possível visualizar na Tabela 5, em relação às dimensões dos Valores do Trabalho, a maior média encontrada foi relativa à Segurança, dentro da modalidade de ensino presencial (4,44). Como afirmam Ros, Schwartz e Surkiss (1999), indivíduos que priorizam a segurança buscam estabilidade no trabalho, com o objetivo de possuir uma renda necessária à manutenção da ordem de suas vidas. Essa média pode ter se destacado no ensino presencial em função de que, embora muitos dos alunos trabalhem, ainda são jovens, com idades entre 16 e 21 anos, o que justifica a expectativa em relação à segurança no futuro profissional.

Por outro lado, nota-se que, para cinco das sete dimensões dos Valores do Trabalho, a modalidade à distância apresentou médias superiores estatisticamente significativas. A média mais alta encontrada foi para a dimensão Universalismo e benevolência $(4,18)$, que envolve aspectos como compreensão, agradecimento, tolerância e proteção do bem-estar das pessoas e da natureza (SCHWARTZ, 2005), seguida da dimensão Autonomia (4,00), cuja média alta pode ser por envolver pessoas que já se encontram em ambientes de trabalho há mais tempo.

Na sequência, o ensino à distância também apresentou maiores médias em relação à modalidade presencial nas dimensões Estimulação $(3,97)$, Autodeterminação $(3,74)$ e Poder $(2,88)$, sendo o Poder a dimensão menos valorizada, caracterizando o público do ensino à distância como menos preocupado com aspectos como status, prestígio ou domínio sobre pessoas e recursos (PORTO; PILATI, 2010).

Em relação às Âncoras de Carreira, pode-se observar que os discentes da modalidade presencial se identificam mais com as âncoras de carreira Desafio puro $(4,50)$ e Autonomia/Independência (4,35). Toit e Coetzee (2012), ao investigarem uma amostra 


\section{VALORES RELATIVOS AO TRABALHO E ÂNCORAS DE CARREIRA: A ÓTICA DE DISCENTES DO \\ ENSINO SUPERIOR NAS MODALIDADES PRESENCIAL E À DISTÂNCIA \\ DOI: http://dx.doi.org/10.5007/1983-4535.2018v11n1p24}

composta por cientistas e engenheiros também identificaram âncoras com conteúdos distintos (estilo de vida, desafio puro e serviço e dedicação a uma causa), sendo as diferenças constatadas associadas às variáveis de perfil, como gênero e faixa etária.

Por outro lado, evidencia-se que as maiores médias ficaram quase todas concentradas na modalidade de ensino à distância, a começar, assim como no ensino presencial, pela dimensão Desafio puro $(4,48)$, seguidas de Segurança e estabilidade $(4,36)$, Serviço/dedicação a uma causa $(4,21)$, Criatividade empreendedora $(3,80)$ e, por último, Gerência Geral $(3,30)$.

Por fim, cabe destacar também que mesmo havendo diferenças significativas entre as modalidades de ensino presencial e à distância, a hierarquia atribuída aos valores e âncoras em ambas as modalidades foi semelhante, o que demonstra certo padrão de concordância quanto à percepção de importância atribuída a cada dimensão estudada.

\section{CONSIDERAÇÕES FINAIS}

O presente trabalho procurou analisar a percepção dos discentes de cursos de graduação presencial e à distância sobre os valores relativos ao trabalho e as âncoras de carreira. Como resultados da análise fatorial da EVT-R, foram obtidos sete fatores relacionados aos Valores Relativos ao Trabalho, os quais apresentam semelhanças com os fatores expostos na literatura por Porto e Pilati (2010), foram eles: Segurança, Poder, Realização, Universalismo e Benevolência, Autonomia, Estimulação e Autodeterminação; e da análise fatorial do Inventário de Âncoras de Carreira foram obtidos seis fatores: Desafio Puro, Segurança e Estabilidade, Autonomia e Independência, Serviço/Dedicação a uma Causa, Criatividade Empreendedora e Gerência Geral.

Em relação às dimensões dos Valores do Trabalho, a maior média encontrada foi relativa à Segurança, dentro da modalidade de ensino presencial. Por outro lado, a modalidade de ensino à distância apresentou médias superiores em Universalismo e benevolência, Autonomia, Estimulação, Autodeterminação e Poder.

Em relação às Âncoras de Carreira, os discentes da modalidade presencial se identificam mais com as âncoras de carreira Desafio puro $(4,50)$ e Autonomia/Independência (4,35), mas as maiores médias prevaleceram na modalidade de ensino à distância, a começar, assim como no ensino presencial, pela dimensão Desafio puro $(4,48)$, seguidas de Segurança e estabilidade $(4,36)$, Serviço/dedicação a uma causa $(4,21)$, Criatividade empreendedora $(3,80)$ e, por último, Gerência Geral $(3,30)$. 
Ressalta-se que mesmo havendo diferenças significativas de percepção entre as modalidades de ensino presencial e à distância, a hierarquia atribuída aos valores e âncoras em ambas foi semelhante, demonstrando certo padrão de concordância quanto à percepção de importância atribuída a cada dimensão estudada.

Considera-se que uma das limitações do estudo foi a realização da pesquisa englobando alunos da modalidade presencial somente do turno noturno, o que pode ter ocasionado distorções nos resultados em razão das possíveis diferenças de perfil entre alunos do noturno e do diurno. Assim, ampliar os estudos nesse âmbito e aprofundar as questões de perfil poderá contribuir e enriquecer análises e conclusões posteriores.

Sugere-se que sejam realizadas pesquisas futuras que visem ampliar o conhecimento acerca dos Valores Relativos ao Trabalho e das Âncoras de Carreira relacionados às modalidades de ensino presencial e à distância.

Considerando a relevância dessas temáticas no contexto laboral e a necessidade de melhor compreensão acerca dos motivos que levam os indivíduos a trabalhar e a tomar decisões sobre suas carreiras, recomenda-se também a realização de pesquisas dessa natureza em outros segmentos, podendo congregar aspectos associados à realização e satisfação no trabalho, permitindo uma análise mais abrangente acerca dos temas.

\section{REFERÊNCIAS}

ABRAHIM, G. S. A Influência dos Valores Humanos nas Decisões de carreira. II Encontro de Gestão de Pessoas e Relações de Trabalho, EnGPR, Curitiba, 2009.

ANDRADE, T., VIEIRA, K. M., ESTIVALETE, V. D. F. B., BENDER FILHO, R. A influência dos valores relativos ao trabalho nas decisões de carreira: um estudo sobre as perspectivas de discentes de instituições de ensino superior. Revista Eletrônica de Administração, v.2, n.3, p.625-657, 2014.

ARETIO, L. G. Educación a distancia hoy. Madrid: Universidad de Educación a Distância. 1994.

ALVES, L. Educação a distância: conceitos e história no Brasil e no mundo. Revista Brasileira de Aprendizagem Aberta e a Distância, v.10, 2011.

CHANG, R. D.; WUNN, K.T.; TSENG, Y. C. A Study Of The Relationships Between Career Orientation, Achievement Motivation, Job Satisfaction, And Intention To Stay For Auditors. Journal of Business And Economics Research, v.1, n.4, 2011. 
COETZEE, M.; SCHREUDER, D. The relation between career anchors, emotional intelligence and employability satisfaction among workers in the service industry. Southern African Business Review, v. 15, n. 3, 2011.

COETZEE, M.; SCHREUDER, D.; TLADINYANE, R.; Organisational commitment and its

relation to career anchors. Southern African Business Review , v.11, n. 1, 2007.

DANZIGER, N.; RACHMAN-MOORE, D.; VALENCY, R. The construct validity of Schein's career anchors orientation inventory. Career Development International, v. 13, n. 1, p. 7-19, 2008.

DUTRA, J. S.; ALBUQUERQUE, L. Âncoras de Carreira. Extraído de Career Anchors de Edgar H. Schein. Adaptado para Administração de Recursos Humanos. São Paulo: FEA-USP, 1996.

ELIZUR, D.; SAGIE, A. Facets of personal values: a structural analysis of life and work values. Applied Psychology: An International Review, v. 48, n.1, p. 73-87, 1999.

FARO, E. S. C.; AMORIM, M. C. S.; TREVISAN, L.; JUNQUEIRA, L. A. P. Âncoras de carreira e transformações no modelo de administração: estudo de caso do Tribunal de Contas da União (TCU). Cadernos EBAPE.BR, v.8, n.4, p. 710-733, 2010.

FERLIN, E. P.; TOZZI, M. J. Desempenho dos alunos da engenharia da computação: turno diurno x noturno. Revista de Ensino de Engenharia, v. 24, n. 2, p. 43-48, 2005.

GILBERT, S. D. How to be a Successful On-Line Student. New York, McGraw-Hill, 2001.

HILTZ, S. The Virtual Classroom: Learning without Limits Via Computer Networks. Albex Publishing, Norwood, NJ, 1993.

HIRSCHI, A. Callings in career: A typological approach to essential and optional components. Journal of Vocational Behavior, v.79, p. 60-72, 2011.

LEUTY, M. E.; HANSEN, J. I. C. Evidence of construct validity for work values. Journal of Vocational Behavior, v.79, 2011.

MORAN, J. M. O Que é Educação a Distância? In: Boletim de Educação a Distância. Brasil, Ministério da Educação, Secretaria de Educação a Distância, 2000.

OLIVEIRA, A. F.; TAMAYO, A. Inventário de perfis de valores organizacionais. Revista de Administração, [S. 1.], v. 39, n. 2, p. 129-140, abr./maio/jun. 2004.

PAULSEN, M. E-Learning: o papel dos sistemas de gestão da aprendizagem na Europa. Colecção formação a distância \& e-Learning, Inofor, 2002.

PORTO, J. B.; PILATI, R. Escala Revisada de Valores Relativos ao Trabalho - EVT-R. Psicologia: Reflexão e Crítica, v. 23, n.1, p. 73-82, 2010. 
PORTO, J. B.; TAMAYO, A. Valores do Trabalho. In: SIQUEIRA, M. M. M. Medidas do Comportamento Organizacional. Porto Alegre: Artmed, 2008.

PORTO, J. B.; TAMAYO, A. Estrutura dos valores pessoais: A relação entre valores gerais e laborais. Psicologia: Teoria e Pesquisa, v. 23, n.1, p. 63-70, 2007.

PORTO, J. B.; TAMAYO, A. Escala de Valores Relativos ao Trabalho - EVT. Psicologia:Teoria e Pesquisa, v. 19, n. 2, p. 145-152, mai./ago. 2003.

REIS, F. L. Do ensino presencial ao Ensino A Distância no contexto universitário na Península Ibérica. Revista Brasileira de Aprendizagem Aberta e a Distância, v. 8, 2009.

ROS, M. Psicologia social dos valores: uma perspectiva histórica. In: ROS, M.; GOUVEIA, V. V. (orgs.). Psicologia Social dos Valores Humanos. São Paulo: Senac, 2006.

ROS, M.; SCHWARTZ, S.H.; SURKISS, S. Basic individual values, work values and the menaning of work. Applied Psychology: An International Review, v.48, n. 2, p. 49-71, 1999.

SCHEIN, E. H. Identidade Profissional: como ajustar suas inclinações e suas opções de trabalho. Tradução de Margarida D. Black. São Paulo: Nobel, 1996.

SCHEIN, E. H. Career Anchors: Discovering your real values. Revised edition. San Diego: Pfeiffer e Company, 1993.

SCHWARTZ, S. H. Valores Humanos básicos: seu contexto e estrutura intercultural. In: TAMAYO, A.; PORTO, J. B. (orgs.). Valores e Comportamento nas Organizações.

Petrópolis: Vozes, 2005. (p. 21-55).

SCHWARTZ, S. H. Universals in the content and structure of values: Theory and empirical tests in 20countries. In: ZANNA, M. (Ed.).Advances in experimental social psychology. New York: Academic Press, 1992.

SOLDANO, S.M. Integrating work and basic values into the Spherical Model of Interests. Journal of Vocational Behavior, v. 78, p. 1-10, 2011.

TOIT, D. M.; COETZEE, M. Archetypal values of science and engineering staff in relation to their career orientations. SA Journal of Industrial Psychology; v.24, p. 1-14, 2012.

WILS, L.; WILS, T.; TREMBLAY, M. Toward a Career Anchor Structure: An Empirical Investigation of Engineers. Industrial Relations, v. 65, n 2, p. 236-256, 2010. 